\title{
Process Parameter Optimization for Selective Laser Melting of 316L Stainless Steel Material using Taguchi's Statistical Design of Experiment Procedure
}

\author{
Gabriel Awuku Dzukey ${ }^{1}$, Ke Yang ${ }^{2}$ \\ College of Mechanical and Electrical Engineering \\ Hohai University, Changzhou, Jiangsu Province, China \\ gadzukey@hhu.edu.cn,dzukeyg@outlook.com; yangke_hhuc@126.com
}

\begin{abstract}
Selective Laser Melting (SLM) is a type of additive manufacturing or 3D printing technology that makes use of a high-power laser beam to completely melt powder material layer upon layer which solidifies to form the desired part or component. In this experimental study, a careful selection of SLM process parameters (laser power, scan speed, hatching distance, and layer height) was done for the selective laser melting of 316L stainless steel powder material to produce samples with maximum density. A statistical procedure was carried out on the experimental data using the Taguchi's design of experimental technique to optimize the carefully selected process parameters. The obtained results were analyzed using analysis of variance (ANOVA) and signal-to-noise (S/N) ratio with the help of Minitab 18 statistical software to determine the optimal parameters and a regression model was also established. The regression model indicates a linear relationship between relative density and the process parameters. Density value higher than $\mathbf{9 5 \%}$ was obtained from this experimental study.
\end{abstract}

Keywords: Taguchi method, SLM, Optimization, 316L Stainless Steel

\section{INTRODUCTION}

Selective laser melting (SLM) is a type of Additive manufacturing (AM) or 3D Printing process that is currently and rapidly being industrialized [1] because it is one of the most promising AM technologies allowing manufacturing of metallic parts from a loose powder. By completely melting the metallic powder; the particles are attached together to produce a sheet of molten powder layer-upon-layer which solidifies to form the part. This manufacturing method is said to be best suited to produce complex and thin-walled components. Its characteristics are really of great advantage to most industries since $3 \mathrm{D}$ printings give more freedom of design and the opportunity to create optimal and lightweight components. Also, the SLM process and most of the 3D printing processes have a common characteristic of being eco-friendly, if compared with conventional machining.

Grade 316L stainless steel is the low carbon version of the 316-standard molybdenum-bearing grade and is immune from sensitization (grain boundary carbide precipitation). Thus, it is extensively used in heavy gauge welded components (over about $6 \mathrm{~mm}$ ), a property suitable for SLM. It is widely used in various applications such as Marine applications, Construction, Medical implants (including pins, screws and orthopedic implants like total hip and knee replacements), Fasteners etc. This imposes some specific requirements on the steel material including, wear resistance, hardness, high compressive strength, lightweight, economical material cost etc., [2]. Since SLM have some characteristics that meet the above specific requirements, there is the need find out the quality of 316L stainless steel manufactured products using SLM.

Despite these several advantages that SLM provides, parts manufactured with this process usually present porosity. Porosity is caused when non-appropriate parameters are used within the build-up process. Elevated levels of porosity lead to a decrease in the relative density value of the SLM pieces, being the cause of poor mechanical properties or even the fracture of it. The ability to produce complex parts is not enough, it must be complemented with high performance and high mechanical properties. Therefore, improvement of the relative density which will decrease the porosity of samples formed by SLM has become the main focus of many experts [3]-[5]. In SLM a high-power laser is used to melt a powder material layer by layer to form a solid part. The build process is controlled by changing the process parameters such as layer thickness, laser power, scanning speed and hatching distance which all affect the build rate and properties of the finished part. For each SLM processed material, a specific range of parameter combinations exists that results in sufficient quality, such as density and desired surface roughness. There is, therefore, the need for an experiment to be conducted to determine a suitable parameter set for each material (in this case SS316L) that will result to produce parts with a very high relative density value. 
The Taguchi method is referred to in literature as one of the most powerful tools for the statistical design of experiments, which considers multi-factors [6]-[9]. It makes use of some representative points to be investigated from a comprehensive test in the form of orthogonal arrays which are highly fractionalized factorial layouts, reducing the number of trials, shorten experiment time and reduce cost. In this paper, the influence of processing parameters on the density of SLM has been studied. The Taguchi, Analysis of Variance (ANOVA) and regression analysis methods, which are statistical experimental procedures, were used for the analysis and optimization of the SLM parameters.

\section{EXPERIMENT}

\section{A. Experimental Equipment}

The experiments were carried out using the SLM 260 3D printer manufactured by the Jiangsu Jiuyi Machinery Co., Ltd., China, which can be represented by the schematic diagram in Fig. 1. The main parameters of the SLM 260 printer are as follows: continuous $\mathrm{Yb}$-fiber laser of $0.4 \mathrm{KW}$ maximum power, $260 \times 260 \times 250 \mathrm{~mm}(\mathrm{~L} \times \mathrm{W} \times \mathrm{H})$ maximum molding size, optical system: HurrySCANLAB 30 with dynamic focus and spot diameter between 80 120um, construction speed: $50-1000 \mathrm{~mm}^{3} / \mathrm{min}$ and of layer thickness between $0.02-0.1 \mathrm{~mm}$.

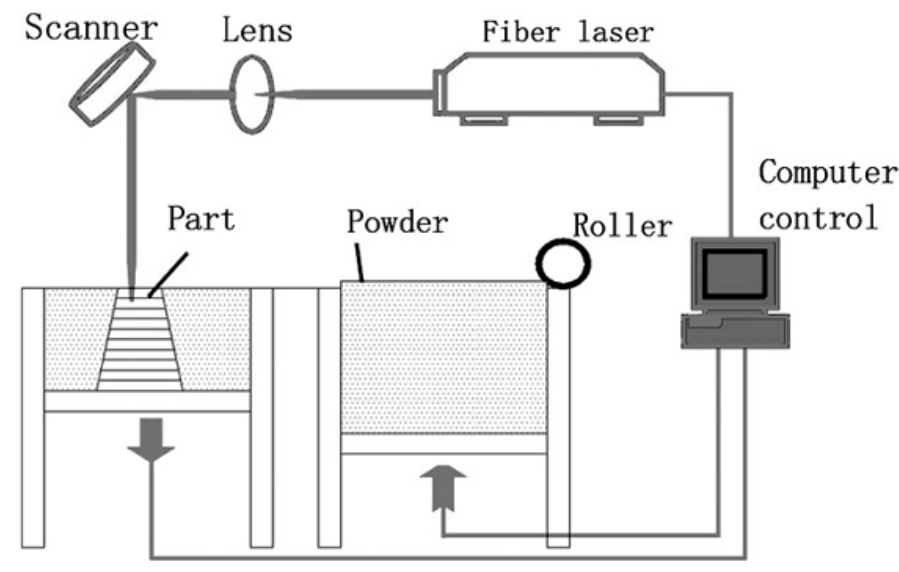

Fig. 1. Schematic diagram of SLM [4]

TABLE. I. Abbreviations

\begin{tabular}{|c|l|}
\hline Abbreviations & \multicolumn{1}{|c|}{ Meaning } \\
\hline $\mathrm{k}$ & the relative density of the part under consideration $(\mathrm{SS} 316 \mathrm{~L})$ \\
\hline $\mathrm{m}_{\mathrm{a}}$ & mass of the part in air \\
\hline $\mathrm{m}_{\mathrm{fl}}$ & mass of the part in fluid \\
\hline$\rho_{\mathrm{fl}}=$ & density of the fluid (density of water $\left.=0.9982 \mathrm{~g} / \mathrm{cm}^{3}\right)$ \\
\hline$\rho_{\mathrm{p}}$ & the density of the part under consideration $\left(\right.$ density of SS316L $\left.=7.9 \mathrm{~g} / \mathrm{cm}^{3}\right)$ \\
\hline $\mathrm{S} / \mathrm{N}$ & signal-to-noise \\
\hline $\mathrm{n}$ & number of tests \\
\hline $\mathrm{y}_{\mathrm{i}}$ & measured characteristics $($ density) from experiments \\
\hline $\mathrm{ANOVA}$ & analysis of variance \\
\hline $\mathrm{S}_{\mathrm{m}}$ & an average of the squares of the sums \\
\hline $\mathrm{S}_{\mathrm{A}}$ & the sum of squares correlated to the control factor A \\
\hline $\mathrm{S}_{\mathrm{T}}$ & the sum of squares of the variance \\
\hline $\mathrm{S}_{\mathrm{E}}$ & the sum of squares of the errors correlated to all controlled factors \\
\hline $\mathrm{N}$ & number of samples in each group \\
\hline $\mathrm{DF}$ & degree of freedom \\
\hline $\mathrm{SS}$ & sum of squares \\
\hline $\mathrm{MS}$ & mean square \\
\hline
\end{tabular}

\section{B. Experimental Material}

The material composition of 316L Stainless Steel powder material is shown in Table II below in percentage (\%). Carbon (C) content being 0.03 maximum, Manganese (Mn) 2.0 maximum, Phosphorus (P) 0.045 maximum, Sulphur (S) 0.03 maximum, Silicon (S) 0.75 maximum, Chromium (Cr) in a range of 16.0-18.0, Nickel (Ni) 10.014.0, Nitrogen constitutes up to 0.10 and the balance constitutes Iron $(\mathrm{Fe})$. 
TABLE II. Chemical Composition of 316LStainless Steel Material

\begin{tabular}{|l|l|l|l|l|l|l|l|l|l|}
\hline $\mathrm{C}$ & $\mathrm{Mn}$ & $\mathrm{P}$ & $\mathrm{S}$ & $\mathrm{Si}$ & $\mathrm{Cr}$ & $\mathrm{Ni}$ & $\mathrm{Mo}$ & $\mathrm{N}$ & $\mathrm{Fe}$ \\
\hline$\leq 0.030$ & $\leq 2.00$ & $\leq 0.045$ & $\leq 0.030$ & $\leq 0.75$ & $16.00 \sim 18.00$ & $10.00 \sim 14.00$ & $2.00 \sim 3.00$ & $\leq 0.10$ & Balance \\
\hline
\end{tabular}

\section{Taguchi Method}

In accordance with the Taguchi method, the procedures are first to identify and select proper quality characteristics according to experimental analysis. Secondly, the selection of the appropriate orthogonal array and assigning of design parameters to conduct the experiment, analysis of the experimental results using $\mathrm{S} / \mathrm{N}$ and ANOVA analyses which are statistical procedures embedded in Minitab, a statistical software package. Finally, the optimal process parameter can be obtained using Minitab [10].

\section{Selection of Process Parameters}

The process parameters were determined according to the Taguchi method using L9 orthogonal array with four (4) factors (laser power, scanning speed, hatching distance, layer height) and three (3) levels as shown below in Table III.

Table III. Factors and Levels

\begin{tabular}{|l|c|c|c|}
\hline Parameters & Level 1 & Level 2 & Level 3 \\
\hline Laser Power(P)/W & 200 & 240 & 280 \\
\hline Scan speed(s)/mm/s & 400 & 500 & 600 \\
\hline Hatching distance $(\mathrm{t}) / \mu \mathrm{m}$ & 50 & 60 & 70 \\
\hline Layer height $(\mathrm{h}) / \mu \mathrm{m}$ & 40 & 50 & 60 \\
\hline
\end{tabular}

\section{E. Recording of Experimental Data}

The samples with the cubic dimension of $10 \mathrm{~mm} \times 10 \mathrm{~mm} \times 10 \mathrm{~mm}$ are printed on steel substrate of dimension $100 \mathrm{~mm} \times 100 \mathrm{~mm} \times 20 \mathrm{~mm}$ using the parameters according to the L9 orthogonal array. The oxygen content in the forming or working chamber of the SLM 3D printer was kept below $0.1 \%$. The relative density measurements of the $316 \mathrm{~L}$ stainless steel samples were based on the Archimedes principle. The mass $m_{a}$ and $m_{f l}$ which represent the masses of the SLM-formed 316L stainless steel samples in air and distilled water respectively are measured with a high-precision electronic balance. The calculations for the samples under consideration follows the equation (2) below:

$$
\rho_{p}=\frac{m_{a}}{m_{a}-m_{f l}} \times \rho_{f l}
$$

Where:

$$
k=\frac{m_{a} \times \rho_{f l}}{\rho_{p}\left(m_{a}-m_{f l}\right)} \times 100
$$

\section{F. Experimental Calculation}

1) Calculation of $S / N$ : "Nominal is best", "smaller is better" and "higher is better" are the three main categories for performing $\mathrm{S} / \mathrm{N}$ ratio analysis with regards to performance characteristics. In this study density is the criterion and the desire is to obtain the highest relative density value. Therefore, the factors with the highest $\mathrm{S} / \mathrm{N}$ ratio values in this experiment gives the best performance. In view of this, the standard requires that among the three categories," higher is better" characteristic-form be used in this case [6]. Below is the formula in equation (3);

$$
\frac{s}{N_{i}}=-10 \log \left(\frac{1}{n} \sum_{i=1}^{n} \frac{1}{y_{i}^{2}}\right) \quad \text { Eq.3 }
$$

2) ANOVA Calculation: The analysis of variance (ANOVA) is performed on the data to study the contribution of all controllable factors and also to determine which factor has the most significant effect on the relative density of the samples produced using SLM. The equations below were used to calculate some of the parameters used in ANOVA [7].

$$
\begin{aligned}
S_{m} & =\frac{\left(\sum_{i=1}^{16} \eta_{i}\right)^{2}}{16} & & \text { Eq.4 } \\
S_{A} & =\frac{\left(\sum_{i=1}^{4} \eta_{A i}\right)^{2}}{N} S_{m} & & \text { Eq.5 } \\
S_{T} & =\sum_{i=1}^{16} \eta_{i}{ }^{S 2} S_{m} & & \text { Eq.6 } \\
S_{E} & =S_{T} \sum S_{A} & & \text { Eq.7 }
\end{aligned}
$$

' $A$ ' is representation for the various factors; laser power, scanning speed, hatching distant and layer height. 


\section{RESULTS AND DISCUSSION}

\section{A. S/N Analysis}

Table IV and Table $\mathrm{V}$ show the results of $\mathrm{S} / \mathrm{N}$ ratio response analysis which indicates the influence of the control parameters (laser power, scan speed, hatching distance, layer thickness) on the relative density values of the SLM printed samples. The difference between the maximum and minimum values of the mean of S/N ratios, also known as the range (delta) was used to determine parameters with the strongest influence [11]. In other words, the larger this difference (delta) value, the higher the influence of the control parameter. According to the analysis in Table $\mathrm{V}$, among all other factors, Laser power was the most influential processing parameter and the strength of influence of the factors decreasingly ranges from laser power, layer height, scan speed, and hatching distance. Fig. 2 and 3 indicate the main effects plots for the $\mathrm{S} / \mathrm{N}$ ratio and mean values of relative density respectively.

1) Influence of Laser Power on the Relative Density: From Fig.2, it can be seen that an increase in the Laser power results in increasing relative density value at different speeds which are indicated by the rise in the $S / \mathrm{N}$ ratio value. The increase is faster between laser powers of $240-280 \mathrm{~W}$ than between $200-240 \mathrm{~W}$. The rising laser power led to the right amount of energy (volumetric energy density) required to properly melt the powder bed, hence the relative density happens to increase with laser power.

2) Effect of Scanning Speed on the Relative Density: The relative density rises with rising scanning speed up to the maximum when the scanning speed is $500 \mathrm{~mm} / \mathrm{s}$ and after declines with increasing relative density. The scanning speed and laser power have a very close relationship and just as the laser power affect the amount of energy required in melting the powder bed, so it is with the scanning speed. Considering the same laser power, lowering the scanning speed will cause an increase in the Volumetric Energy Density (VED), since the time spent in a spot is reduced and vice versa. Less or too low VED values causes improper melting of the powder bed leading to the presence of pores in the built samples and lower density values. Likewise, too high VED values lead to evaporation of powder bed causing pores as well. In this case, the effect of the scanning speed of 400$600 \mathrm{~mm} / \mathrm{s}$ among other factors has little influence on the relative density values. Between the speed of $400-500 \mathrm{~mm}$ $/ \mathrm{s}$, the relative density value increases from $88.09-8.47 \%$ and decrease by $1.06 \%$ when the speed is $500-600 \mathrm{~mm} / \mathrm{s}$.

3) Effects of the Hatching Distance on the Relative Density: The density changed increasingly but with a very small percentage of almost insignificant values with increasing hatching distance (a total change of $0.25 \%$ relative density). From Table V, it can be seen that among other factors hatching distance has the least influence on the relative density in this experiment. A very small scan distance or hatching distance can cause overlapping of laser beam resulting in a very high concentrated laser energy at the overlapping area causing over burning of the powder bed and this affects the density of the samples. Likewise, a wider hatching distance results in improper melting of the powder between laser beam tracks, which also affects the density of the printed samples.

TABLE IV. Relative Density and S/N Ratio obtained using Taguchi's L 9 Orthogonal Array

\begin{tabular}{|l|l|l|l|l|l|l|}
\hline No. & $\begin{array}{l}\text { Laser } \\
\text { power(W) }\end{array}$ & $\begin{array}{l}\text { Scan } \\
\text { speed(mm/s) }\end{array}$ & $\begin{array}{l}\text { Hatching } \\
\text { distance }(\boldsymbol{\mu m})\end{array}$ & $\begin{array}{l}\text { Layer } \\
\text { thickness }(\boldsymbol{\mu m})\end{array}$ & $\begin{array}{l}\text { Relative } \\
\text { Density }(\mathbf{\%})\end{array}$ & S/N Ratio \\
\hline 1 & 200 & 400 & 50 & 40 & 83.52 & 38.43581 \\
\hline 2 & 200 & 500 & 60 & 50 & 84.02 & 38.48765 \\
\hline 3 & 200 & 600 & 70 & 60 & 80.95 & 38.16434 \\
\hline 4 & 240 & 400 & 60 & 60 & 85.58 & 38.64745 \\
\hline 5 & 240 & 500 & 70 & 40 & 88.11 & 38.9005 \\
\hline 6 & 240 & 600 & 50 & 50 & 86.69 & 38.75938 \\
\hline 7 & 280 & 400 & 70 & 50 & 95.16 & 39.56909 \\
\hline 8 & 280 & 500 & 50 & 60 & 93.27 & 39.39484 \\
\hline 9 & 280 & 600 & 60 & 40 & 94.58 & 39.51599 \\
\hline
\end{tabular}


TABLE V. Response Table for Signal to Noise Ratios- Larger is better

\begin{tabular}{|c|c|c|c|c|}
\hline Level & Laser Power $(\mathbf{W})$ & Scan Speed $(\mathbf{m m} / \mathbf{s})$ & Scan Distance $(\boldsymbol{\mu m})$ & Layer Thickness $(\boldsymbol{\mu m})$ \\
\hline 1 & 38.36 & 38.88 & 38.86 & 38.95 \\
2 & 38.77 & 38.93 & 38.88 & 38.94 \\
3 & 39.49 & 38.81 & 38.88 & 38.74 \\
\hline Delta & 1.13 & 0.11 & 0.02 & 0.22 \\
\hline Rank & 1 & 3 & 4 & 2 \\
\hline
\end{tabular}

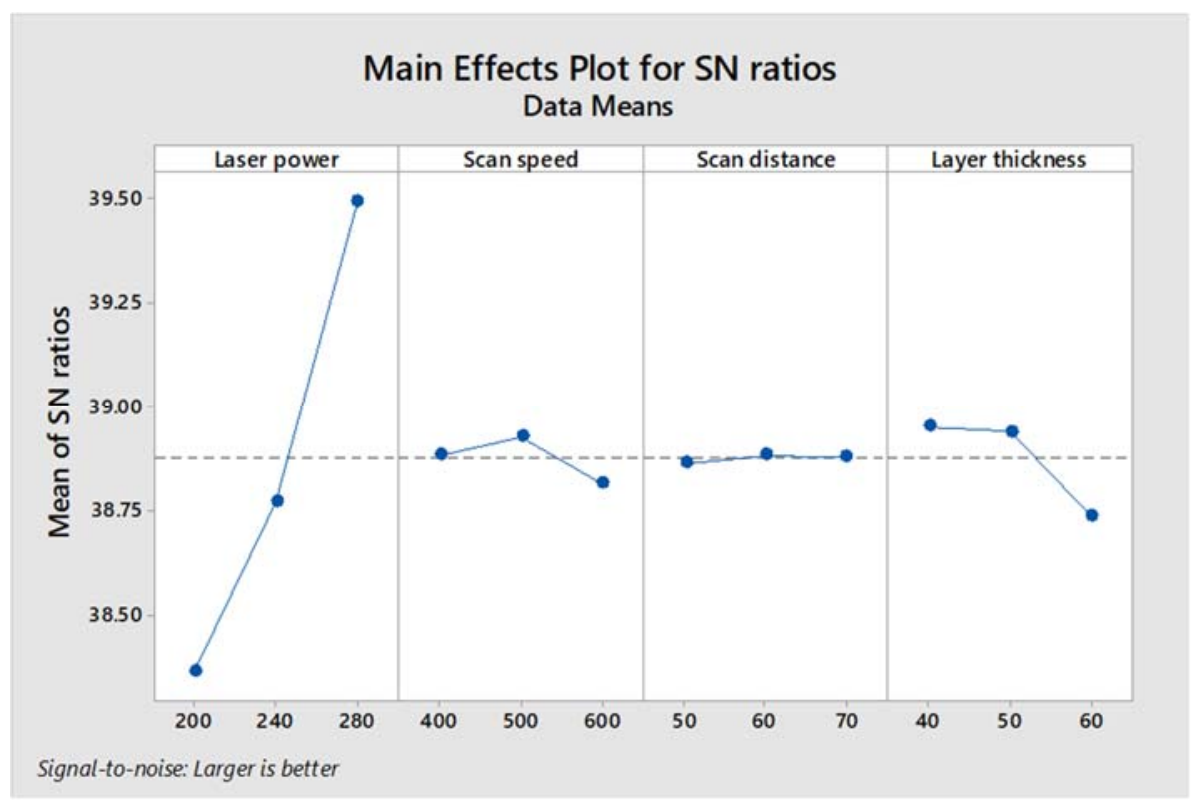

Fig.2. Main effect plots for $\mathrm{S} / \mathrm{N}$ ratio

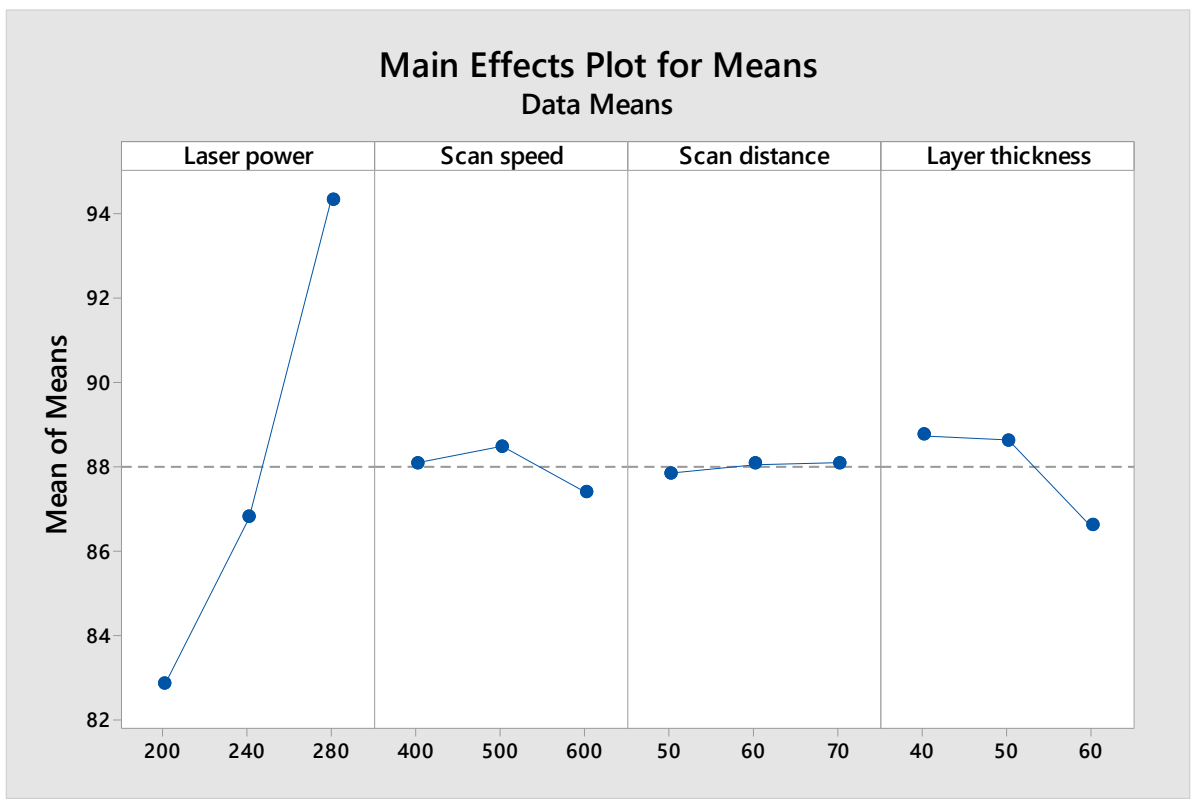

Fig.3. Main effects plots for means of Relative Density

\section{B. ANOVA Analysis}

The ANOVA analysis was done to find the process parameters significantly influencing the relative density value of the SLM printed samples. This was done for a confidence level of $95 \%$, which is for a significance level of $\alpha=0.05$. Table VI and Table VII show the analysis of variance results using Minitab Statistical Software package, which makes use of the formulas in Equations (4)-(7). 
As it can be seen in Table VI, the test of significance cannot be performed because P-values could not be calculated and this is because the error term has a zero (0) Degree of Freedom (DOF or DF). According to statistics, in cases such as this, pooling of insignificant factors should be considered, this adds them to the error term thereby making the DOF of the error term non-zero, but a factor is pooled when it fails the test of significance. Unfortunately, the test of significance can only be done when the error term has nonzero DOF. As a rule, even if a test of significance is not possible, pooling should be considered by starting with pooling a factor if its influence (using S to compare instead of P-value) is $10 \%$ or lower than the most influential factor [12]. This rule was applied to recalculate the ANOVA terms in Table VII with the help of the Minitab Software. The P values for Laser power and layer height were less than 0.05 and are therefore the significant factors influencing the response (relative density). The scanning speed has little effect.

TABLE VI. Analysis of Variance before pooling

\begin{tabular}{|l|c|c|c|c|c|c|c|}
\hline Factors & DF & Seq SS & Contribution & Adj SS & Adj MS & F-Value & P-Value \\
\hline Laser power & 2 & 205.013 & $95.12 \%$ & 205.013 & 102.507 & $*$ & $*$ \\
Scan speed & 2 & 1.730 & $0.80 \%$ & 1.730 & 0.865 & $*$ & $*$ \\
Scan distance & 2 & 0.115 & $0.05 \%$ & 0.115 & 0.058 & $*$ & $*$ \\
Layer thickness & 2 & 8.672 & $4.02 \%$ & 8.672 & 4.336 & $*$ & $*$ \\
Error & 0 & $*$ & $*$ & $*$ & $*$ & & \\
\hline \multicolumn{1}{|c|}{ Total } & 8 & 215.531 & $100.00 \%$ & & & & \\
\hline
\end{tabular}

TABLE VII. Analysis of Variance after pooling

\begin{tabular}{|c|c|c|c|c|c|c|c|}
\hline Source & DF & Seq SS & Contribution & Adj SS & Adj MS & F-Value & P-Value \\
\hline Laser power & 2 & 205.013 & $95.12 \%$ & 205.013 & 102.507 & 1775.52 & 0.001 \\
Scan speed & 2 & 1.730 & $0.80 \%$ & 1.730 & 0.865 & 14.99 & 0.063 \\
Layer thickness & 2 & 8.672 & $4.02 \%$ & 8.672 & 4.336 & 75.10 & 0.013 \\
Error & 2 & 0.115 & $0.05 \%$ & 0.115 & 0.058 & & \\
\hline Total & 8 & 215.531 & $100.00 \%$ & & & & \\
\hline
\end{tabular}

\section{Regression Analysis}

A multiple linear regression equation, which models a relationship between the process parameters and the response was also developed using Minitab 18 statistical software package. Table VIII indicates the results of ANOVA regression analysis, it can be seen that regression coefficient (R-sq) was $95.65 \%$ which is an indication of the change in the value of independent variables (process parameters) corresponding to the unit change in the dependent variable (relative density). In other words, $95.65 \%$ of the variability can be explained by the model. The positive coefficient associated with laser power in the regression equation below suggests that the relative density increases with increasing laser power likewise the negative coefficient of the scan speed and layer thickness suggest increasing scanning speed and layer thickness decreases the relative density of the SLM printed samples.

The regression equation is as follows;

Relative Density $=60.51+0.1438$ Laser power -0.00340 Scan speed -0.1068 Layer thickness $\quad$ Eq. 8

TABLE VIII. ANOVA Regression Analysis

\begin{tabular}{|c|c|c|c|c|c|}
\hline Source & DF & Adj SS & Adj MS & F-Value & P-Value \\
\hline Regression & 3 & 206.147 & 68.716 & 36.61 & $\begin{array}{c}0.001 \\
\text { (Significant) }\end{array}$ \\
Error & 5 & 9.385 & 1.877 & & \\
\hline Total & 8 & 215.531 & & & \\
\hline \multicolumn{7}{|c|}{ R-sq=95.65\% R-sq(adj) $=93.03 \%$} \\
\hline
\end{tabular}




\section{Optimization}

An optimization study was performed to find out the optimal processing conditions at which the desirable (maximum) relative density values of the SLM printed samples can be accomplished [13]. The aim is to obtain the maximum relative density without any limitation on the process parameters [9]. Minitab 18 was used to analyze the experimental data. As shown in Table IX, each process parameter and the response (relative density) have been given a specific goal. By using Minitab, it is required that the value of the response should be as large as possible (usually taking values impossible to achieve) to obtain the optimized parameters and or optimum solutions based on the optimized parameters. The optimum solutions obtained using the Minitab software are displayed in Table X, which indicates that the optimized parameter set of the printed SLM samples are: $280 \mathrm{~W}$ laser power, $500 \mathrm{~mm} / \mathrm{s}$ scan speed and $40 \mu \mathrm{m}$ layer thickness.

TABLE IX. Criteria for Numerical Optimization

\begin{tabular}{|c|c|c|c|}
\hline Name & Goal & Lower Limit & Upper Limit \\
\hline Laser Power $(\mathrm{W})$ & in range & 200 & 280 \\
Scan speed $(\mathrm{mm} / \mathrm{s})$ & in range & 400 & 600 \\
Hatching distance $(\mu \mathrm{m})$ & in range & 50 & 70 \\
Layer thickness $(\mu \mathrm{m})$ & in range & 40 & 60 \\
Relative Density $(\%)$ or response & maximize & 80.95 & target $=100$ \\
\hline
\end{tabular}

TABLE X. Optimal Solution as obtained by Minitab 18 for Relative Density

\begin{tabular}{|cccccc|}
\hline Solution & $\begin{array}{c}\text { Laser } \\
\text { power }\end{array}$ & $\begin{array}{c}\text { Scan } \\
\text { speed }\end{array}$ & $\begin{array}{c}\text { Layer } \\
\text { thickness }\end{array}$ & $\begin{array}{c}\text { Relative } \\
\text { Density Fit }\end{array}$ & $\begin{array}{c}\text { Composite } \\
\text { Desirability }\end{array}$ \\
\hline 1 & 280 & 500 & 40 & 95.5667 & 1.00000 (selected) \\
2 & 280 & 500 & 50 & 95.4533 & 1.00000 \\
3 & 280 & 400 & 40 & 95.1867 & 1.00000 \\
4 & 280 & 400 & 50 & 95.0733 & 0.99390 \\
5 & 280 & 600 & 40 & 94.5067 & 0.95402 \\
\hline
\end{tabular}

\section{CONCLUSION}

This experimental study made use of Taguchi's Design of Experiment method to estimate the optimal processing parameters in Selective laser melting (SLM) of 316L stainless steel material with an emphasis on obtaining highly dense formed products. The analysis of the experimental data was performed by varying the process parameters up to three levels. The significant parameters contributing to the relative density of formed SLM samples were determined using ANOVA and S/N ratio analysis, a mathematical model which can be used to predict relative density values was also proposed by the help of Minitab 18 statistical software package. Within the scope of this research work, the following conclusion among other factors can be drawn:

1. The optimum levels of process parameters for maximizing the relative density were determined. The optimal condition for printing highly dense (above $95 \%$ relative density) SLM product was found out to be Laser power $=280 \mathrm{~W}$, Scan speed $=500 \mathrm{~mm} / \mathrm{s}$, Layer thickness (layer height) $=40 \mu \mathrm{m}$ and a Hatching distance around $40-70$ $\mu \mathrm{m}$ or using an acceptable working range.

2. In accordance with the results obtained from the statistical analysis, it was found out that, the Laser power was the most significant parameter or factor affecting the density with a percentage contribution of $95.12 \%$.

3. The regression analysis performed showed that the linear multiple regression model established demonstrated a very good relationship between process parameters and the response (relative density) with a high regression coefficient (95.65\%).

4. Minitab Statistical software package can be used for optimizing the SLM process parameters and determining the corresponding optimum processing conditions.

\section{ACKNOWLEDGMENT}

The contribution of the Jiangsu Jiuyi Machinery Co., Ltd, Kunshan-China, where the SLM samples were printed for this experimental study, is greatly appreciated. 


\section{REFERENCES}

[1] Spears T.G. and Gold S.A., (2016). 'In-Process Sensing in Selective Laser Melting (SLM) Additive Manufacturing'. Integrating Materials and Manufacturing Innovation, a Springer Open Journal. DOI 10.1186/s40192-016-0045-4. Cited 10 February 2018 from https:/link.springer.com/content/pdf/10.1186\%2Fs40192-016-0045-4.pdf

[2] (2004) AZO Materials website 'Stainless Steel - Grade 316L - Properties, Fabrication and Applications (UNS S31603)', [Online]. Available: https

[3] Gu H., Gong H., Pal D., Rafi K., Starr T., Stucker B.,(2013), Influences of Energy Density on Porosity and Microstructure of Selective Laser Melted 17-4PH Stainless Steel Cited 17 February 2018 from http://sffsymposium.engr.utexas.edu/Manuscripts/2013/2013-37Gu.pdf

[4] Sun J., Yang Y., Wang D., Parametric optimization of selective laser melting for forming Ti6Al4V samples by Taguchi method. Optics \& Laser Technology 49 (2013) 118-124

[5] Laakso, P.; Riipinen, T.; Laukkanen, A.; Andersson, T.; Jokinen, A.; Revuelta, A.; Ruusuvuori, K. Optimization and simulation of SLM process for high-density H13 tool steel parts. Phys. Procedia 2016, 83, 26-35.

[6] Canel T, Kaya A.U, Celik B. Parameter optimization of nanosecond laser for micro drilling on PVC by Taguchi method. Optics \& Laser Technology 2012; 44:2347-53.

[7] Yang DX, Li XY, He DY, Nie ZR, Huang H. Optimization of weld bead geometry in laser welding with filler wire process using Taguchi's approach. Optics Laser Technology 2012; 44:2020-5.

[8] Li CH, Tsai MJ, Yang CD. Study of optimal laser parameters for cutting QFN packages by Taguchi's matrix method. Optics \& Laser Technology 2007; 39:786-95.

[9] Benyounis K.Y., Olabi AG, Hashmi MSJ. Multi-response optimization of CO2 laser-welding process of austenitic stainless steel. Optics \& Laser Technology 2008; 40:76-87.

[10] Yang W H, Tarng YS. Design optimization of cutting parameters for turning operations based on the Taguchi method. Journal of Materials Processing Technology 1998; 64:122-9.

[11] Kumar S, Choudhary A. K. S., Anwar J., and Sharma V., Optimization of Process parameters in Direct Metal Deposition Technique using Taguchi method. International Journal of Mechanical Engineering and Technology, 7(3), 2016, pp. 225235.http://www.iaeme.com/currentissue.asp?JType=IJMET\&VType=7\&IType=3

[12] Roy R. K., 2001, Design of Experiments Using the Taguchi Approach: 16 Steps to Product and Process Improvement, John Wiley \& Sons, Inc. (US) - ISBN 0-471-36101-1. (211).

[13] Eltawahni HA, Olabi AG, Benyounis K.Y. Effect of process parameters and optimization of CO2 laser cutting of ultra-high-performance polyethylene. Materials \& Design 2010; 31:4029-38.

\section{AUTHOR PROFILE}

Gabriel Awuku Dzukey is currently studying for an MSc. in Mechanical Engineering, at the College of Mechanical and Electrical Engineering, Hohai University, Changzhou Campus, China. He studied for his BSc. in Agricultural Engineering from the Kwame Nkrumah University of Science and Technology, Kumasi-Ghana (2015). His current research interest is in Laser Additive Manufacturing.

Ke Yang is currently a Professor at the College of Mechanical and Electrical Engineering, Hohai University, Changzhou, China. He holds a Ph.D. from the University of Science and Technology, Wuhan, China (2009). His area of research includes Metal Material, Welding and Metallurgy, and Surface Engineering. 